\title{
Podcast: Women's health pioneer Dr. May Cohen
}

$\mathrm{W}$

omen's health pioneer Dr. May Cohen will join other luminaries in the Canadian Medical Hall of Fame at a ceremony on Apr. 14.

Cohen entered medicine at a time when less than $10 \%$ of graduating physicians were female and textbook medical research was based on a $70 \mathrm{~kg}$ male body.

She went on to shatter that malecentric paradigm, co-founding Canada's first Women's Health Office at McMaster University in Hamilton, Ont., as well as the Women's Health InterSchool Curriculum Committee for Ontario medical schools. Her research on the careers of female physicians also drew unprecedented attention to issues of gender and equality within the profession.

In a podcast interview, Cohen reflects on her legacy and the changing status of women in medicine. - Lauren Vogel, CMAJ

Tune in at SoundCloud.com.

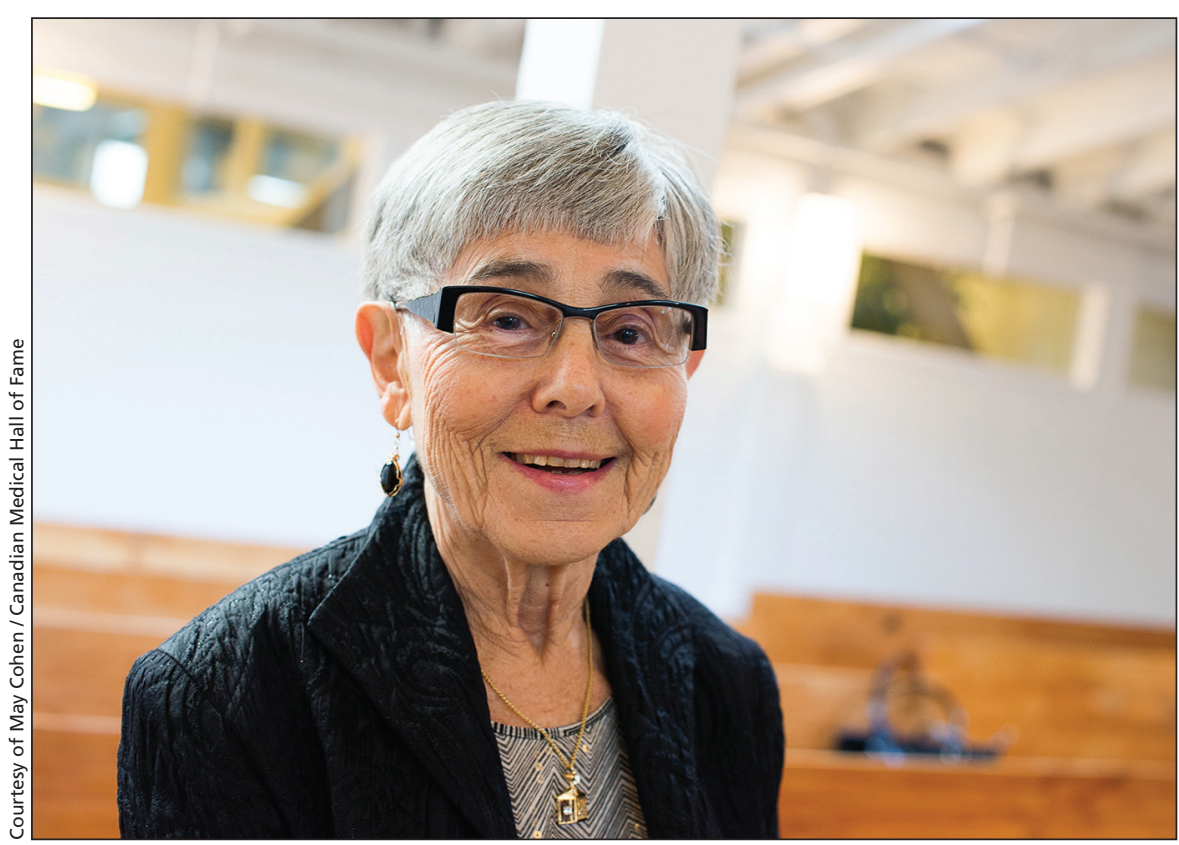

Dr. May Cohen championed the inclusion of women's health in medical training at a time when students were still collectively addressed as "gentlemen." 